\title{
AragoJ: A free, open-source software to aid single camera photogrammetry studies
}

\author{
Francisco Aleixo $^{1}$ | Seán A. O'Callaghan ${ }^{2}$ | Luís Ducla Soares ${ }^{3}$ (D) | Paulo Nunes ${ }^{3}$ | \\ Rui Prieto $^{4,5}$ (D)
}

\author{
${ }^{1}$ Aptoide S.A., Lisbon, Portugal \\ ${ }^{2}$ Galway-Mayo Institute of Technology, \\ Galway, Ireland \\ ${ }^{3}$ Instituto de Telecomunicações, Instituto \\ Universitário de Lisboa (ISCTE-IUL), Lisbon, \\ Portugal \\ ${ }^{4}$ MARE-Marine and Environmental Sciences \\ Centre, Lisbon, Portugal \\ ${ }^{5}$ OKEANOS and IMAR Centre at the \\ University of the Azores, Ponta Delgada, \\ Portugal
}

\section{Correspondence}

Rui Prieto

Email: rcabprieto@gmail.com

\section{Funding information}

This work was supported by the Azores 2020 Operational Programme and Fundo Regional da Ciência e Tecnologia (FRCT) through research project WATCH IT (Acores-01-0145-FEDER-000057) co-funded by FEDER, COMPETE, QREN, POPH, FSE and the Portuguese Ministry for Science and Education. We also acknowledge funds provided by Fundação para a Ciência e Tecnologia (FCT) to MARE, Okeanos, and Instituto de Telecomunicações through strategic projects UID/MAR/04292/2019, UIDB/05634/2020, and UID/EEA/50008/ 2019 , respectively. RP is supported by FCT through a postdoctoral grant (SFRH/ BPD/108007/2015).

Handling Editor: Samantha Price

\begin{abstract}
1. Close-range photogrammetry (CRP) is a well-established technique to retrieve quantitative information from objects using photography. CRP is often used in morphology studies when the direct handling of individuals is unpractical or unethical, or to reduce processing costs and time. Although multiple software to extract quantitative information from 3D reconstructions of objects exist, tools for 2D CRP are scarce and often tailored for specific applications.

2. We present AragoJ, a cross-platform, open-source, Java based software designed to integrate and streamline all 2D CRP workflow steps in a single program.

3. AragoJ allows the user to perform all the main tasks involved in obtaining measurements from digital pictures, namely: (1) performing camera calibration and correcting radial picture distortions; (2) calculating a scaling factor either by: (a) utilizing a scale in the picture, or (b) based on camera specifications (focal distance and digital sensor size) and distance to object; (3) measuring and scaling the relevant traits in the photographs; (4) obtaining information from pictures' digital metadata files; and (5) exporting measurements and metadata to a comma separated values file.
\end{abstract}

4. AragoJ was designed to be versatile and unconstrained, in order to be useful for 2D CRP studies across multiple disciplines. The software, source code and detailed documentation are available from https://github.com/AzWhaleLab/AragoJ.

\section{KEYWORDS}

2D photogrammetry studies, AragoJ, close-range photogrammetry, image processing, ImageJ, Java, morphometrics, OpenCV

\section{1 | INTRODUCTION}

Quantitative analysis of size and shape (morphometrics) is fundamental for the study of organisms' ecology and evolution (Elewa, 2010; Reyment, 1996; Rohlf, 1990).

Close-range photogrammetry (CRP) is a technique widely used to remotely obtain measurements of objects and organisms, by scaling measurements taken on their 2D photographic reproductions (planimetric measurements), or from photography-based 3D reconstructions (Kraus, 2011; Luhmann, Robson, Kyle, \& Harley, 2006). The technique has been long used in morphometric studies to expedite acquiring and processing data (Hsiang et al., 2018; Ivosevic, Han, \& Kwon, 2017; Zou et al., 2014), for conservation and ethical concerns (Whitehead \& Gordon, 1986; Whitehead \& Payne, 1981) or to obtain data on organisms that are difficult to locate, manipulate or are inaccessible in other ways (e.g. Breuer, Robbins, \& Boesch, 2007; Deakos, 2010; Durban et al., 2016; Letessier, Juhel, Vigliola, \& Meeuwig, 2015; Muneza et al., 2019; Willisch, Marreros, 
\& Neuhaus, 2013). Another incentive for using 2D photogrammetry is its relative low cost when compared to direct measurement, which is often made clear in publication titles, by the use of terms such as 'inexpensive', 'low-cost' or 'cost-efficient' (e.g. Dawson, Bowman, Leunissen, \& Sirguey, 2017; Dawson, Chessum, Hunt, \& Slooten, 1995; Langlois et al., 2010; Letessier et al., 2015). Despite its widespread use, 2D CRP is not without caveats, and can be affected by several error sources (Dai, Feng, \& Hough, 2014; Scherz, 1974; Wenhao, 2001). Nonetheless, the method has been shown to be both accurate and to produce suitable levels of precision, when properly implemented (e.g. Dawson et al., 2017; Deakos, 2010; Galbany et al., 2016; Grochowsky, Alaways, Siskey, Most, \& Kurtz, 2006; Jadejaroen, Hamada, Kawamoto, \& Malaivijitnond, 2015; Jeffreys, Rowat, Marshall, \& Brooks, 2013; Monkman, Hyder, Kaiser, \& Vidal, 2019; Weisgerber, Medill, \& McLoughlin, 2015).

The surge in computing power in the last decades, combined with the development of consumer-grade high-definition digital photography and democratization of low-cost unmanned aerial vehicles led to a rapid increase in the utilization of CRP for 3D scene reconstruction, using either stereogrammetric or 'structure from motion' methods (Micheletti, Chandler, \& Lane, 2015; Remondino, Spera, Nocerino, Menna, \& Nex, 2014). Accordingly, an ever-increasing number of softwares for 3D scene reconstruction and measurement are available (Rupnik, Daakir, \& Pierrot Deseilligny, 2017). Notwithstanding, 3D CRP is not suited for all applications. Methods for 3D scene reconstruction are not well-suited for moving subjects, and usually rely in the acquisition of a large number of images taken from different angles, which is not always feasible. Additionally, in many applications, 2D and 3D metrics are comparable, making the use of 2D CRP more desirable due to its simplicity and lower associated costs (Birgfeld et al., 2013; Cardini, 2014).

Yet, and paradoxically, software specifically designed to aid in obtaining simple planimetric measurements in 2D CRP are scarce and often tailored to specific problems, narrowing their applicability (e.g. Burnett et al., 2018; Hsiang et al., 2018). Instead, 2D CRP studies often make use of image editing software to obtain measurements from digital photographic reproductions (e.g. FrankeGromberg, Schüler, Hermanussen, \& Scheffler, 2010; Galbany et al., 2016; Gašparič, Hyžný, Jovanović, Ćorić, \& Vrabac, 2019; Leurs, O'Connell, Andreotti, Rutzen, \& Vonk Noordegraaf, 2015; Rhee, 2018). Measurements are subsequently transcribed to a digital database and scaled, adding to the lengthy process of data acquisition and preparation prior to analysis, and also increasing the chances of transcription errors compromising data quality (Kim, Choi, Hong, Kim, \& Lee, 2003). Any other operations, such as calibrating the camera, undistorting images or retrieving image metadata, usually require separate processing on other software (Balletti, Guerra, Tsioukas, \& Vernier, 2014; Wehkamp \& Fischer, 2014).

The scientific image-analysis software ImageJ (Abramoff, Magalhães, \& Ram, 2004) stands out as an exception and powerful tool for 2D CRP. With over 30 years of continuous development, Image J has become one of the most widely used scientific imaging software (Schneider, Rasband, \& Eliceiri, 2012). Among its strengths are the cross-platform nature, modular architecture with numerous extensions (macros and plugins) and the free and open-source nature of the software (Abramoff et al., 2004; Schneider et al., 2012). However, one of the qualities of ImageJ is also a challenge for new users, as the sheer number of extensions makes selecting, maintaining and learning to work with the appropriate add-ons a complex and time-consuming task (Collins, 2007). Moreover, most of these extensions are tailored for medical imaging, microscopy and material sciences (Collins, 2007; Schneider et al., 2012), not being well-suited for other 2D CRP applications.

Here, we introduce AragoJ, an open-source Java application designed specifically with the purpose of streamlining 2D CRP tasks. Apart from small variations, most 2D CRP studies follow a similar workflow (e.g. Dawson et al., 2017; Deakos, 2010; Gale, Renouf, \& Worthy, 1994; Jadejaroen et al., 2015; Meise, Mueller, Zein, \& Trillmich, 2014; Rothman et al., 2008; Shrader, Ferreira, \& Aarde, 2006) consisting of the following steps: (1) camera calibration and picture distortion correction; (2) calculating a scaling factor either by: (a) utilizing fiducial markers, or (b) based on camera specifications (focal distance and digital sensor size) and distance to object; (3) measuring and scaling the relevant traits in the photographs; (4) extracting information embedded in the picture's metadata; and (5) transcribing measurements and metadata to a digital database.

AragoJ includes tools that address all of those steps, through a user-friendly Graphical User Interface (GUI). This way, the processing time can be greatly reduced and transcription errors are avoided, as all measurements, calculation results and metadata selections made using AragoJ are automatically exported as a tabulated comma separated values (CSV) file, accepted by most analysis and editing software.

Unlike other software, such as Automorph (Hsiang et al., 2018), AragoJ does not implement automatic object recognition and measurement intentionally, because that usually requires high image quality and strict orientation, and constrains the measurements to a set of pre-defined metrics. The automation offered by software such as Automorph is invaluable to reduce processing time under controlled conditions (Hsiang et al., 2018), but also limits applicability when that is not the case. AragoJ was designed to be flexible enough to handle situations that are not addressed by existing software, being useful for a wide range of users, while not competing with other applications optimized for more specific tasks.

AragoJ software releases and source code are openly available on GitHub (https://github.com/AzWhaleLab/AragoJ), and an illustrated user manual is also available with detailed information on tools and functionalities.

\section{2 | SOFTWARE DESCRIPTION}

AragoJ has a multi-modular architecture implemented in Java for its cross-platform capabilities. The GUI is implemented through JavaFX framework comprising three main panels (Navigation, Work and [Info]rmation), along with Menu and Tool bars (Figure 1). Navigation is 


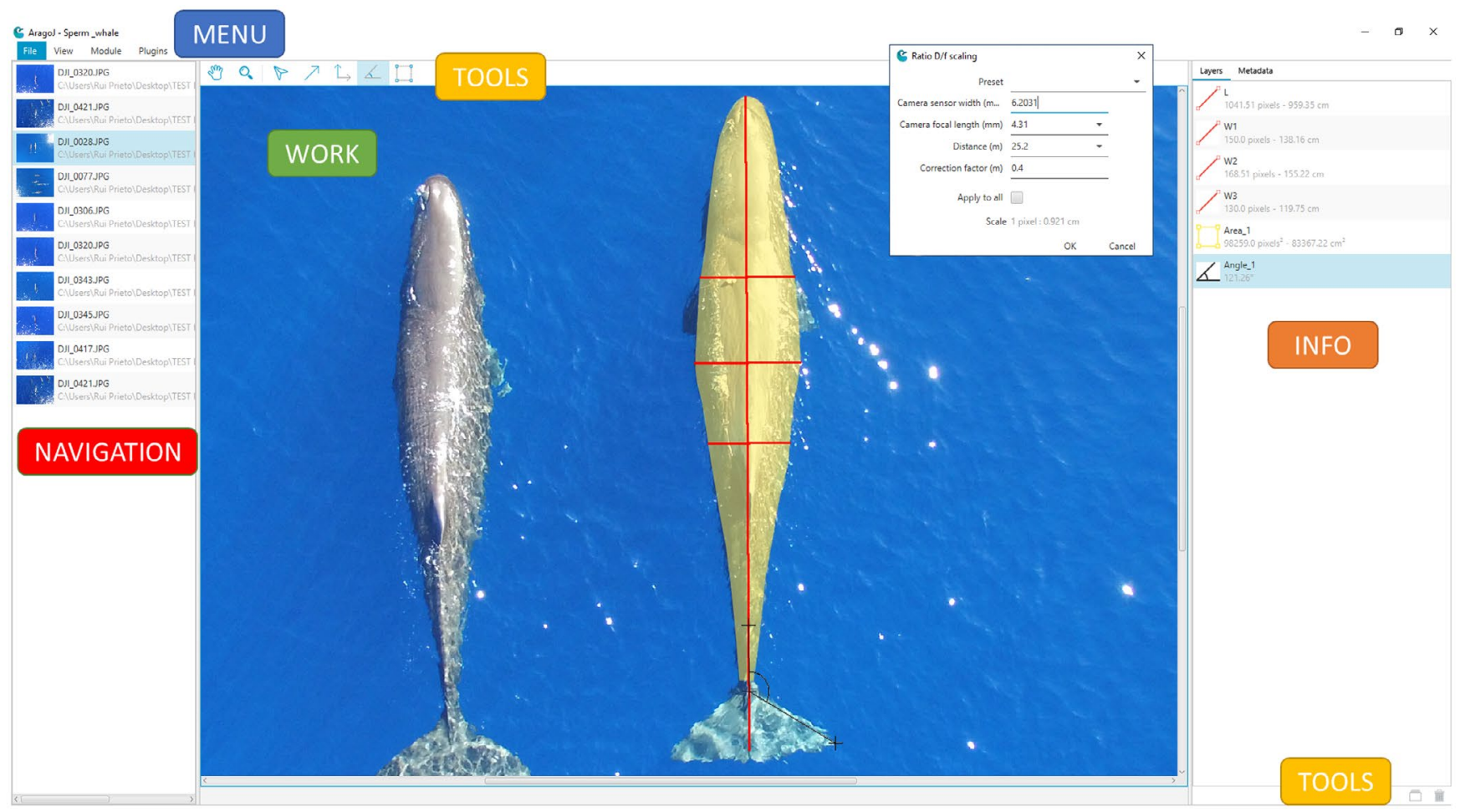

FIGURE 1 Graphical user interface of AragoJ, showing the different components of the main screen. The pop-up window to configure distance-based scaling is also shown (to the left of the Info panel). Measurements (body length and widths, area and angle of fluke with body axis) of a sperm whale Physeter macrocephalus from an aerial picture are visible in the Work panel. Scaled measurements using distance from camera to object are visible in the Info panel

where thumbnails and names of imported images are presented; the Work panel is the main working area, where image manipulation and measuring is performed; the Info panel is sub-divided in two tabs: (a) Metadata tab, where the metadata embedded in the images are displayed and (b) Layer tab, where information about measurements and results from calculations are displayed.

The software consists of seven modules: Camera Calibration; Lens Distortion Correction; Image I/O (Input-Output and Metadata Reader); Measuring; Scaling and Units Conversion; Mathematical Expressions; and Session Handling. In conjunction, these modules comprise a complete pipeline for data extraction and exporting (Figure 2). Functions of each module are described in detail in the following sections.

\section{1 | Camera Calibration}

Camera calibration is essential to scale measurements made on the photographic projections (Kraus, 2011). Lenses used in true metric cameras produce images with negligible distortion, preserving straight lines and right angles (Kraus, 2011). However, lenses used in most consumer-grade cameras warp the image projection, resulting in negative (barrel) or positive (pin-cushion) radial distortion patterns, eliciting the need to undistort images using an appropriate calibration model (Carbonneau \& Dietrich, 2017). AragoJ includes a module for camera self-calibration using the OpenCV library
(Bradski, 2000). Space constraints preclude a detailed description of the self-calibration method, but comprehensive information can be found in Hartley and Zisserman (2004) and Bradski and Kaehler (2008). Very briefly, camera intrinsic parameters for calibration are calculated by analysing multiple photographs of a planar calibration pattern, taken at different random angles (Zhang, 2000). The resulting calibration matrix is written to a file that can subsequently be used for distortion correction. Since self-calibration models do not generalize well for all camera lens types, AragoJ offers two calibration algorithms (Figure 2). Distortion models for cameras using nearrectilinear lenses can be computed using the Bouguet's algorithm implemented in OpenCV (Bouguet, 2015; Bradski \& Kaehler, 2008), based on the method presented by Tsai (1987) and Zhang (2000). Additionally, AragoJ also implements the generic model proposed by Kannala and Brandt (2006), specifically designed to handle large radial distortions caused by fish-eye lenses.

\section{2 | Lens Distortion Correction}

The Lens Distortion Correction module uses OpenCV functions to correct radial distortion in images, based on a calibration model produced by the Camera Calibration module. Images can be batch processed and undistorted images are saved with a suffix ('_u') relative to the original names, preserving the original images unchanged. 


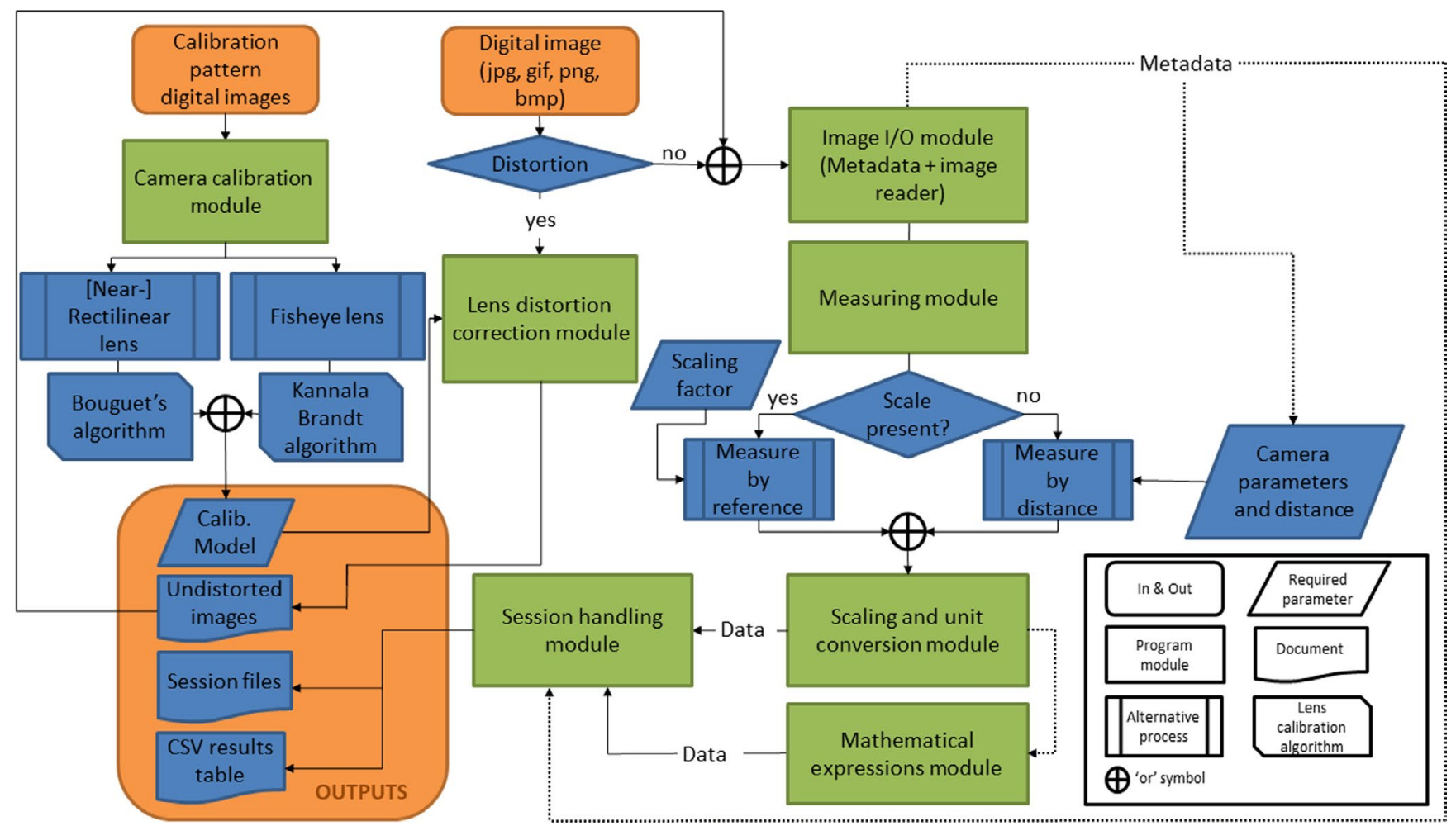

FIGURE 2 Scheme of module interactions and high-throughput of close-range 2D photogrammetry workflow using AragoJ. Dotted lines denote optional information traffic. CSV, comma separated values

\section{3 | Image I/O}

The Image I/O module is responsible for reading and writing images, including pixel and metadata information. AragoJ accepts images in jpg, gif, bmp and png formats natively. Support for other image formats can be added through plugins, consisting of simple Java library projects packaged in a JAR file. Guidance on how to create plugins is available on the GitHub repository. A plugin adding support to over 150 microscopy file formats, using the Bio-Formats library released by the Open Microscopy Environment Consortium (https://openm icroscopy.org) is included in AragoJ distributions after version 0.61, which can also be used as an example for the creation of additional plugins.

The application reads and presents the metadata inscribed in digital images EXIF information (JEITA, 2002), which is useful for finding and using relevant information (geolocation, date and time, camera and image specifications, custom information from sensors, etc.). Metadata entries can be individually selected for exporting (Figure 3), as well as be directly imported in some of the other AragoJ tools.

\section{4 | Measuring}

AragoJ includes tools for linear, area and angle measurements (Figure 1). The linear measurement tool accepts any number of segments, allowing for the measurement of irregular and curved shapes. Additionally, linear measurements can be made at userspecified angles from a reference line (Figure 1), helping to easily take parallel or perpendicular measurements (or at any other angle).

Apart from angles, all measurements are taken in pixel units prior to scaling (see below). AragoJ allows sub-pixel values, and three pixel selection options are available: free (line segments can start and end at any position inside a pixel), 0.5 pixel (line segments can start and end either at the centre or the edge of a pixel) and 1.0 pixel (line segments can only start and end at the edge of a pixel). These options allow controlling for unrealistic precision.

Polygon area is calculated from coordinate geometry, using Equation 1:

$$
\text { Area }=\left|\frac{\left(x_{1} y_{2}-y_{1} x_{2}\right)+\left(x_{2} y_{3}-y_{2} x_{3}\right)+\cdots+\left(x_{n} y_{1}-y_{n} x_{1}\right)}{2}\right|,
$$

with $x_{n}$ and $y_{n}$ being the coordinates of vertex $n$. Since the method is not applicable for area calculation of self-intersecting polygons, these are first decomposed using the Java class FlatteningPathlterator.

All measurements are recorded and named automatically, as 'layers', and presented in the Layers tab, under the Info panel. The user can easily rename layers, in order to standardize the output data table fields. 


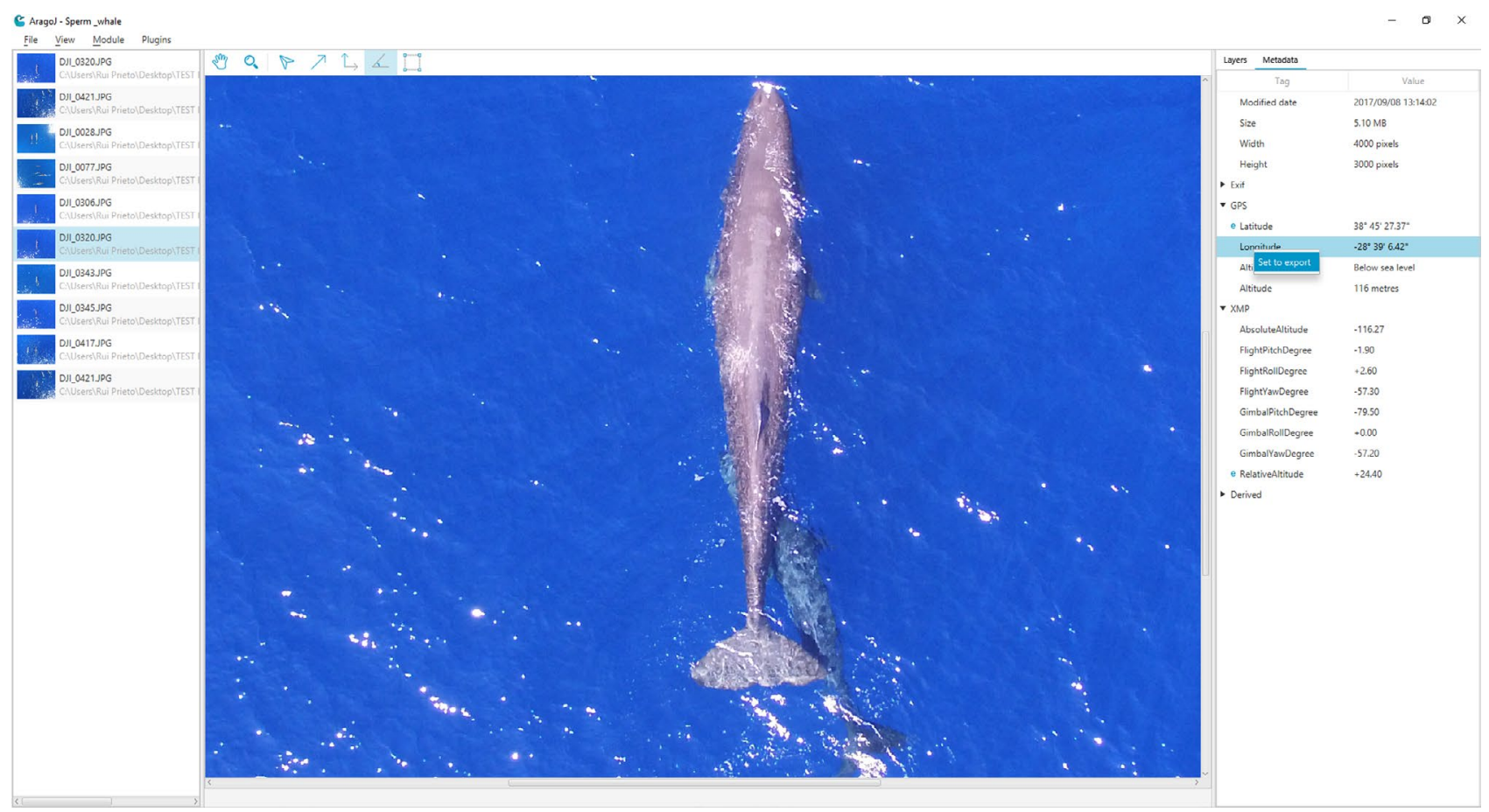

FIGURE 3 Graphical user interface showing the Metadata tab. Some of the picture metadata are visible, while others are hidden under the EXIF and Derived headers. Metadata entries that were selected for exporting are signaled with an 'e' symbol before the metadata tag

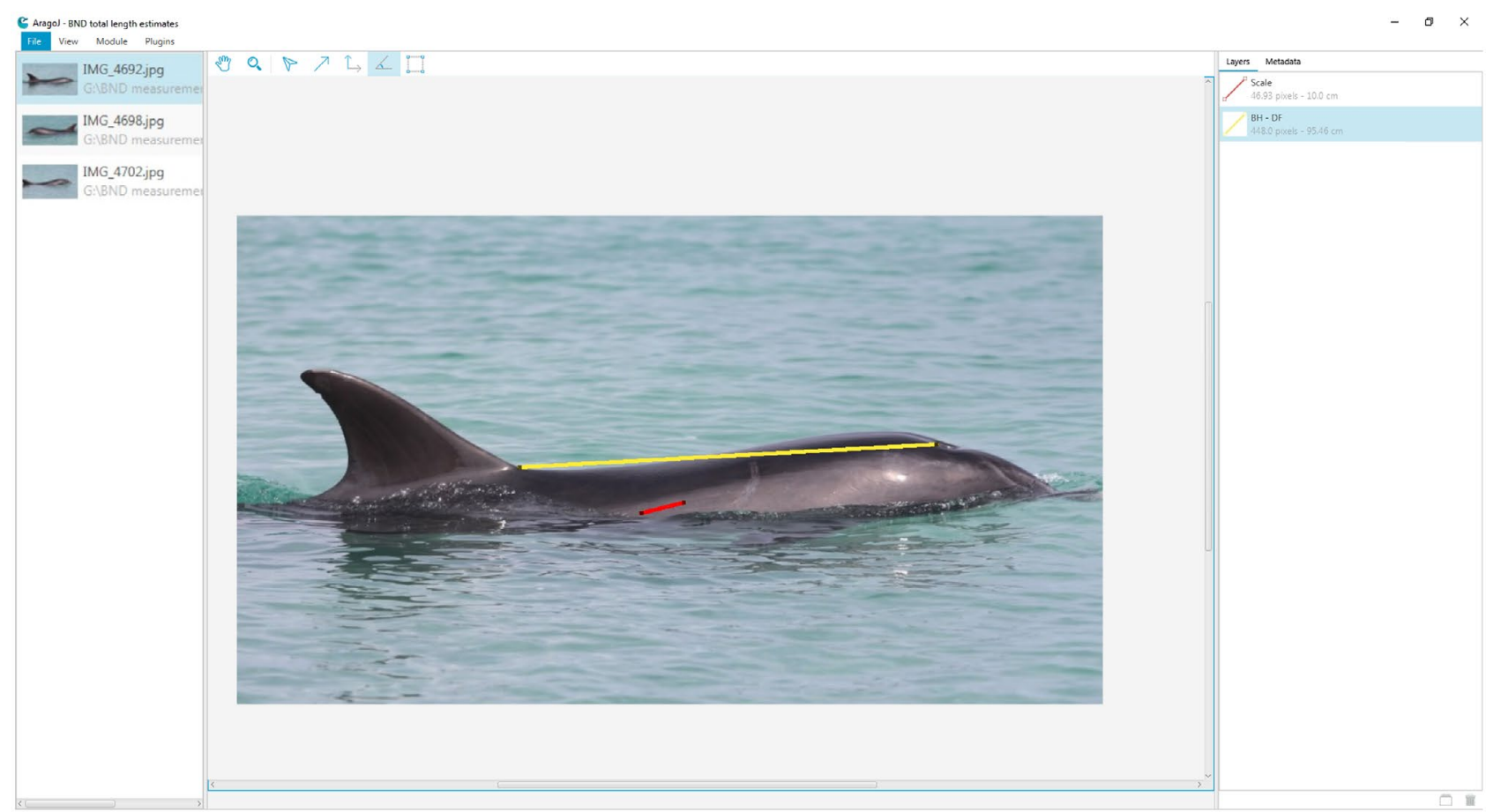

FIGURE 4 Example of reference-based scaling in AragoJ. Parallel lasers are projected on the body of a free-swimming bottlenose dolphin Tursiops truncatus creating a scale (shorter line segment, in red) of known size, that is used by AragoJ to scale other measurements (longer line segment, in yellow). Results from conversion from pixel to metric units can be seen in the Info panel, on the right side of the image

\subsection{Scaling and Unit Conversion}

The Scaling and Unit Conversion module is responsible for scaling measurements from pixel to metric units. For convenience, the module also includes a tool to convert from metric to other units. Two methods are available for scaling measurements taken on the photographs: (a) reference-based (Figure 4), using fiducial marks imprinted in the image; or (b) distance-based (Figure 1), using the 
camera sensor size and focal length, combined with distance to object, to calculate the scaling factor applying the similarity of triangles principle (Kraus, 2011).

Reference-based scaling is calculated using Equation 2:

$$
M_{\mathrm{cm}}=\left(\frac{M_{\mathrm{px}} \times S_{\mathrm{cm}}}{S_{\mathrm{px}}}\right) \text {, }
$$

where $M_{\mathrm{cm}}$ stands for the scaled trait measurement in centimetres (cm), $M_{p x}$ is the length of the same trait in pixel units, $S_{c m}$ is the true length of the scale in $\mathrm{cm}$ and $S_{\mathrm{px}}$ is the length of the scale in pixel units.

In distance-based scaling, the calculation of the scaling factor uses Equation 3:

$$
M_{\mathrm{cm}}=M_{\mathrm{px}} \times\left(\frac{\mathrm{Sw} \times(D+\beta) \times 100}{\mathrm{Fl} \times \mathrm{imW}}\right) \text {, }
$$

where $M_{\mathrm{cm}}$ stands for the scaled trait measurement in $\mathrm{cm}, M_{\mathrm{px}}$ is the same trait measured in pixel units, $\mathrm{Sw}$ is the width of the camera sensor in millimetres $(\mathrm{mm}), D$ is the distance of the camera to the object $(\mathrm{cm}), \mathrm{Fl}$ is the focal length $(\mathrm{mm})$ and $\mathrm{imW}$ is the image width in pixel units (which is automatically obtained from the metadata). $\beta$ is a correction factor for the camera to object distance. For example, the height reported by barometric altimeters used in drones is referenced to the take-off location and can differ from the true height relative to the location where the image was taken; if that difference is known, $\beta$ can be used to correct for that. $\mathrm{Fl}$ and Sw can often be obtained directly from camera manufacturers. Alternatively, a vast database of sensor specifications is maintained by OpenMGV (https://github.com/openMVG).

One caveat with both scaling methods is the square pixels assumption, which in some rare cases is violated (Manthey \& Kowerko, 2019). Nevertheless, the vast majority of modern digital camera sensors utilize square pixels (Godding, 2007).

\subsection{Mathematical Expressions}

AragoJ includes a module for creating and storing mathematical expressions that can be called inside the software and produce results using the measurements made over an image as variables. This is useful to quickly calculate derived variables, for example, using allometric relations.

\section{7 | Session Handling}

The Session Handling module is responsible for saving session information to a file, and managing sessions throughout the life cycle of the application. A session is akin to a 'project' in image editing software, referring to all work done by the user that can be saved. This module specifically handles two cases: (a) opening and saving session information; and (b) exporting measurements, calculations and selected metadata to a CSV file.

\section{3 | CONCLUSIONS AND FUTURE WORK}

We believe that AragoJ is a seamless, convenient and efficient software package to undertake a wide range of $2 \mathrm{D}$ photogrammetry studies within one application, without being tailored to a particular task. This makes AragoJ highly versatile in its uses for CRP across multiple disciplines. In fact, despite having been developed as a tool aimed at helping in ecological studies, the principles and workflow involved are equally applicable in architecture, anthropology, forensics, archaeology and palaeontology studies.

The software utilizes some well-known libraries (such as OpenCV) to manipulate and obtain quantitative information from images. These were chosen for being robust, with well-established and tested methods. These libraries are well-documented, enabling the user to understand how some of the more complex tools (such as camera calibration and distortion correction) work, and to account for any biases that may apply. The architecture of AragoJ allows taking full advantage of these libraries with the aim of optimizing the workflow involved in 2D CRP, in order to improve efficiency and reduce processing time and errors. Additionally, it can be easily extended with new functionalities through the creation of plugins.

AragoJ was created as a stand-alone and portable application so it can be used in most situations, and shared easily. We feel that these are strong qualities and intend to maintain them in future releases. However, we are aware that AragoJ and ImageJ (Abramoff et al., 2004) are complementary in many ways. Thus, an AragoJ plugin for ImageJ is planned for those users who prefer to work with the latter software. Similarly, we also plan to create a mobile version of AragoJ, to improve its utility in fieldwork situations, including direct import capabilities from mobile device cameras.

\section{AUTHORS' CONTRIBUTIONS}

R.P. conceived the software, led the preparation of the manual and participated in testing beta versions; F.A. led the development of AragoJ software; S.A.O. played a key role in testing beta versions, and provided substantial contributions to the manual; L.D.S. and P.N. mentored F.A. and supported software development. All authors participated in the preparation of the manuscript.

\section{DATA AVAILABILITY STATEMENT}

AragoJ is developed through GitHub at https://github.com/AzWha leLab/AragoJ. The source code for v0.6.1, described here, is available under the Apache License, Version 2.0, and is deposited in zenodo https://doi.org/10.5281/zenodo.3660975 (Aleixo, O'Callaghan, Ducla Soares, Nunes, \& Prieto, 2020).

\section{ORCID}

Luís Ducla Soares (iD https://orcid.org/0000-0001-9738-639X Rui Prieto (iD https://orcid.org/0000-0002-0354-2572 


\section{REFERENCES}

Abramoff, M., Magalhães, P., \& Ram, S. J. (2004). Image processing with ImageJ. Biophotonics International, 11, 36-42.

Aleixo, F., O'Callaghan, S. A., Ducla Soares, L., Nunes, P., and Prieto, R. (2020). Data from: AragoJ: A free, open-source software to aid single camera photogrammetry studies. zenodo, https://doi.org/10.5281/ zenodo.3660975

Balletti, C., Guerra, F., Tsioukas, V., \& Vernier, P. (2014). Calibration of action cameras for photogrammetric purposes. Sensors, 14, 17471-17490. https://doi.org/10.3390/s140917471

Birgfeld, C. B., Saltzman, B. S., Luquetti, D. V., Latham, K., Starr, J. R., \& Heike, C. L. (2013). Comparison of two-dimensional and threedimensional images for phenotypic assessment of craniofacial microsomia. The Cleft Palate-Craniofacial Journal, 50, 305-314. https://doi. org/10.1597/11-173

Bouguet, J. Y. (2015). Camera calibration toolbox for Matlab. Retrieved from http://www.vision.caltech.edu/bouguetj/calib_doc/

Bradski, G. (2000). The OpenCV library. Dr Dobb's Journal of Software Tools, 25, 120-125.

Bradski, G., \& Kaehler, A. (2008). Learning OpenCV: Computer vision with the OpenCV library. Sebastopol, CA: O'Reilly Media.

Breuer, T., Robbins, M. M., \& Boesch, C. (2007). Using photogrammetry and color scoring to assess sexual dimorphism in wild western gorillas (Gorilla gorilla). American Journal of Physical Anthropology, 134, 369-382. https://doi.org/10.1002/ajpa.20678

Burnett, J. D., Lemos, L., Barlow, D., Wing, M. G., Chandler, T., \& Torres, L. G. (2018). Estimating morphometric attributes of baleen whales with photogrammetry from small UASs: A case study with blue and gray whales. Marine Mammal Science, 35, 108-139. https://doi. org $/ 10.1111 / \mathrm{mms} .12527$

Carbonneau, P. E., \& Dietrich, J. T. (2017). Cost-effective non-metric photogrammetry from consumer-grade sUAS: Implications for direct georeferencing of structure from motion photogrammetry. Earth Surface Processes and Landforms, 42, 473-486. https://doi.org/ 10.1002/esp.4012

Cardini, A. (2014). Missing the third dimension in geometric morphometrics: How to assess if 2D images really are a good proxy for 3D structures? Hystrix, the Italian Journal of Mammalogy, 25, 73-81.

Collins, T. J. (2007). ImageJ for microscopy. Imaging Frontiers, 43, S25-S30. https://doi.org/10.2144/000112517

Dai, F., Feng, Y., \& Hough, R. (2014). Photogrammetric error sources and impacts on modeling and surveying in construction engineering applications. Visualization in Engineering, 2, 2. https://doi. org/10.1186/2213-7459-2-2

Dawson, S. M., Bowman, M. H., Leunissen, E., \& Sirguey, P. (2017). Inexpensive aerial photogrammetry for studies of whales and large marine animals. Frontiers in Marine Science, 4, 366. https://doi.org/ 10.3389/fmars.2017.00366

Dawson, S. M., Chessum, C. J., Hunt, P. J., \& Slooten, E. (1995). An inexpensive, stereophotographic technique to measure sperm whales from small boats. Report of the International Whaling Commission, 45, 431-436.

Deakos, M. H. (2010). Paired-laser photogrammetry as a simple and accurate system for measuring the body size of free-ranging manta rays Manta alfredi. Aquatic Biology, 10, 1-10. https://doi.org/10.3354/ab00258

Durban, J. W., Moore, M. J., Chiang, G., Hickmott, L. S., Bocconcelli, A., Howes, G., ... LeRoi, D. J. (2016). Photogrammetry of blue whales with an unmanned hexacopter. Marine Mammal Science, 32, 1510-1515. https://doi.org/10.1111/mms.12328

Elewa, A. M. T. (2010). Why morphometrics? In A. M. T. Elewa (Ed.), Morphometrics for nonmorphometricians (pp. 3-7). Heidelberg, Germany; Dordrecht, The Netherlands; London, UK; New York, NY: Springer-Verlag.

Franke-Gromberg, C., Schüler, G., Hermanussen, M., \& Scheffler, C. (2010). Digital 2D-Photogrammetry and direct anthropometry -
A comparing study on test accomplishment and measurement data. Anthropologischer Anzeiger, 68, 11-20. https://doi.org/10.1127/00035548/2010/0012

Galbany, J., Stoinski, T. S., Abavandimwe, D., Breuer, T., Rutkowski, W., Batista, N. V., ... McFarlin, S. C. (2016). Validation of two independent photogrammetric techniques for determining body measurements of gorillas. American Journal of Primatology, 78, 418-431. https://doi. org/10.1002/ajp.22511

Gale, R., Renouf, D., \& Worthy, G. A. J. (1994). Use of bioelectrical impedance analysis to assess body composition of seals. Marine Mammal Science, 10, 1-12. https://doi.org/10.1111/j.1748-7692.1994.tb003 85.x

Gašparič, R., Hyžný, M., Jovanović, G., Ćorić, S., \& Vrabac, S. (2019). Middle Miocene decapod crustacean assemblage from the Tuzla Basin (Tušanj, Bosnia and Herzegovina), with a description of two new species and comparison with coeval faunas from Slovenia. Palaeontologia Electronica, 22(1), 1-21. https://doi.org/10.26879/894

Godding, R. (2007). Camera calibration. In A. Hornberg (Ed.), Handbook of machine vision (pp. 333-360). Weinheim, Germany: John Wiley \& Sons. https://doi.org/10.1002/9783527610136.ch5

Grochowsky, J. C., Alaways, L. W., Siskey, R., Most, E., \& Kurtz, S. M. (2006). Digital photogrammetry for quantitative wear analysis of retrieved TKA components. Journal of Biomedical Materials Research Part B: Applied Biomaterials, 79B, 263-267. https://doi.org/10.1002/ jbm.b.30537

Hartley, R., \& Zisserman, A. (2004). Multiple view geometry in computer vision (2nd ed.). Cambridge, UK: Cambridge University Press.

Hsiang, A. Y., Nelson, K., Elder, L. E., Sibert, E. C., Kahanamoku, S. S., Burke, J. E., ... Hull, P. M. (2018). AutoMorph: Accelerating morphometrics with automated $2 \mathrm{D}$ and $3 \mathrm{D}$ image processing and shape extraction. Methods in Ecology and Evolution, 9, 605-612.

Ivosevic, B., Han, Y.-G., \& Kwon, O. (2017). Calculating coniferous tree coverage using unmanned aerial vehicle photogrammetry. Journal of Ecology and Environment, 41, 10. https://doi.org/10.1186/ s41610-017-0029-0

Jadejaroen, J., Hamada, Y., Kawamoto, Y., \& Malaivijitnond, S. (2015). Use of photogrammetry as a means to assess hybrids of rhesus (Macaca mulatta) and long-tailed (M. fascicularis) macaques. Primates, 56, 77-88. https://doi.org/10.1007/s10329-014-0450-2

Jeffreys, G. L., Rowat, D., Marshall, H., \& Brooks, K. (2013). The development of robust morphometric indices from accurate and precise measurements of free-swimming whale sharks using laser photogrammetry. Journal of the Marine Biological Association of the United Kingdom, 93, 309-320. https://doi.org/10.1017/S0025315412001312

JEITA. (2002). Exchangeable image file format for digital still cameras: Exif Version 2.2. Tokyo, Japan: Japan Electronics and Information Technology Industries Association.

Kannala, J., \& Brandt, S. S. (2006). A generic camera model and calibration method for conventional, wide-angle, and fish-eye lenses. IEEE Transactions on Pattern Analysis and Machine Intelligence, 28, 1335-1340. https://doi.org/10.1109/TPAMI.2006.153

Kim, W., Choi, B.-J., Hong, E.-K., Kim, S.-K., \& Lee, D. (2003). A taxonomy of dirty data. Data Mining and Knowledge Discovery, 7, 81-99.

Kraus, K. (2011). Photogrammetry: Geometry from images and laser scans (2nd ed.). Berlin, Germany: de Gruyter.

Langlois, T. J., Harvey, E. S., Fitzpatrick, B., Meeuwig, J. J., Shedrawi, G., \& Watson, D. L. (2010). Cost-efficient sampling of fish assemblages: Comparison of baited video stations and diver video transects. Aquatic Biology, 9, 155-168. https://doi.org/10.3354/ab00235

Letessier, T. B., Juhel, J.-B., Vigliola, L., \& Meeuwig, J. J. (2015). Low-cost small action cameras in stereo generates accurate underwater measurements of fish. Journal of Experimental Marine Biology and Ecology, 466, 120-126. https://doi.org/10.1016/j.jembe.2015.02.013

Leurs, G., O'Connell, C. P., Andreotti, S., Rutzen, M., \& Vonk Noordegraaf, H. (2015). Risks and advantages of using surface laser 
photogrammetry on free-ranging marine organisms: A case study on white sharks Carcharodon carcharias. Journal of Fish Biology, 86, 1713-1728.

Luhmann, T., Robson, S., Kyle, S. A., \& Harley, I. A. (2006). Close range photogrammetry: Principles, techniques and applications. Caithness, UK: Whittles Publishing.

Manthey, R., \& Kowerko, D. (2019). Hexagonal image generation by virtual multi-grid-camera. In W. Karwowski \& T. Ahram (Eds.), Intelligent human systems integration 2019 (pp. 17-22). Cham, Switzerland: Springer International Publishing.

Meise, K., Mueller, B., Zein, B., \& Trillmich, F. (2014). Applicability of single-camera photogrammetry to determine body dimensions of pinnipeds: Galapagos sea lions as an example. PLoS ONE, 9, e101197. https://doi.org/10.1371/journal.pone.0101197

Micheletti, N., Chandler, J. H., \& Lane, S. N. (2015). Structure from motion (SFM) photogrammetry. In L. E. Clarke \& J. M. Nield (Eds.), Geomorphological Techniques, online ed. (pp. 1-12). London, UK: British Society for Geomorphology.

Monkman, G. G., Hyder, K., Kaiser, M. J., \& Vidal, F. P. (2019). Accurate estimation of fish length in single camera photogrammetry with a fiducial marker. ICES Journal of Marine Science. https://doi.org/10.1093/ icesjms/fszO30

Muneza, A. B., Ortiz-Calo, W., Packer, C., Cusack, J. J., Jones, T., Palmer, M. S., ... Montgomery, R. A. (2019). Quantifying the severity of giraffe skin disease via photogrammetry analysis of camera trap data. Journal of Wildlife Diseases, 55, 770. https://doi.org/10.7589/2018-06-149

Remondino, F., Spera, M. G., Nocerino, E., Menna, F., \& Nex, F. (2014). State of the art in high density image matching. The Photogrammetric Record, 29, 144-166. https://doi.org/10.1111/phor.12063

Reyment, R. A. (1996). An idiosyncratic history of early morphometrics. In L. F. Marcus, M. Corti, A. Loy, G. J. P. Naylor, \& D. E. Slice (Eds.), Advances in morphometrics (pp. 15-22). New York, NY and London, UK: Plenum Publishing Corporation.

Rhee, S. C. (2018). Differences between Caucasian and Asian attractive faces. Skin Research and Technology, 24(1), 73-79. https://doi. org/10.1111/srt.12392

Rohlf, F. J. (1990). Morphometrics. Annual Review of Ecology and Systematics, 21, 299-316. https://doi.org/10.1146/annurev.es.21.110190.001503

Rothman, J. M., Chapman, C. A., Twinomugisha, D., Wasserman, M. D., Lambert, J. E., \& Goldberg, T. L. (2008). Measuring physical traits of primates remotely: The use of parallel lasers. American Journal of Primatology, 70, 1191-1195. https://doi.org/10.1002/ajp.20611

Rupnik, E., Daakir, M., \& Pierrot Deseilligny, M. (2017). MicMac - A free, open-source solution for photogrammetry. Open Geospatial Data, Software and Standards, 2, 14. https://doi.org/10.1186/s40965-0170027-2

Scherz, J. P. (1974). Errors in photogrammetry. Photogrammetric Engineering, 40, 493-500. https://doi.org/10.1016/0148-9062(74)91981-0
Schneider, C. A., Rasband, W. S., \& Eliceiri, K. W. (2012). NIH Image to ImageJ: 25 years of image analysis. Nature Methods, 9, 671-675. https://doi.org/10.1038/nmeth.2089

Shrader, A. M., Ferreira, S. M., \& Aarde, R. J. V. (2006). Digital photogrammetry and laser rangefinder techniques to measure African elephants. South African Journal of Wildlife Research, 36, 1-7.

Tsai, R. Y. (1987). A versatile camera calibration technique for highaccuracy 3D machine vision metrology using off-the-shelf TV cameras and lenses. IEEE Journal on Robotics and Automation, 3, 323-344. https://doi.org/10.1109/JRA.1987.1087109

Wehkamp, M., \& Fischer, P. (2014). A practical guide to the use of consumerlevel digital still cameras for precise stereogrammetric in situ assessments in aquatic environments. Underwater Technology, 32, 111-128.

Weisgerber, J. N., Medill, S. A., \& McLoughlin, P. D. (2015). Parallel-laser photogrammetry to estimate body size in free-ranging mammals. Wildlife Society Bulletin, 39, 422-428. https://doi.org/10.1002/wsb.541

Wenhao, F. (2001). The specific character of limit errors in close range photogrammetry. Geo-spatial Information Science, 4, 50-56. https:// doi.org/10.1007/BF02826924

Whitehead, H., \& Gordon, J. C. D. (1986). Methods of obtaining data for assessing and modeling sperm whale populations which do not depend on catches. Reports of the International Whaling Commission, 8, 149-165.

Whitehead, H., \& Payne, R. (1981). New techniques for assessing populations of right whales without killing them. In J. Gordon Clark (Ed.), Mammals in the sea. Vol. 3: General papers and large cetaceans (pp. 189-209). Rome, Italy: FAO.

Willisch, C. S., Marreros, N., \& Neuhaus, P. (2013). Long-distance photogrammetric trait estimation in free-ranging animals: A new approach. Mammalian Biology, 78, 351-355. https://doi.org/10.1016/j. mambio.2013.02.004

Zhang, Z. (2000). A flexible new technique for camera calibration. IEEE Transactions on Pattern Analysis and Machine Intelligence, 22, 1330-1334. https://doi.org/10.1109/34.888718

Zou, X., Mõttus, M., Tammeorg, P., Torres, C. L., Takala, T., Pisek, J., ... Pellikka, P. (2014). Photographic measurement of leaf angles in field crops. Agricultural and Forest Meteorology, 184, 137-146. https://doi. org/10.1016/j.agrformet.2013.09.010

How to cite this article: Aleixo F, O'Callaghan SA, Ducla Soares L, Nunes P, Prieto R. AragoJ: A free, open-source software to aid single camera photogrammetry studies. Methods Ecol Evol. 2020;11:670-677. https://doi.org/10.1111/

2041-210X.13376 